\title{
Hospital staff practical skills and theoretical knowledge in inhaled aerosol therapy: a single centre cross-sectional observational study
}

\author{
Martina Santambrogio ${ }^{1,2}$, Marta Lazzeri ${ }^{3}$, Gianluca Bonitta ${ }^{2}$, Riccardo Guarise ${ }^{4}$, Edoardo Simonetta ${ }^{1,2}$, \\ Francesco Blasi ${ }^{1,2}$, Emilia Privitera ${ }^{1,5}$ \\ ${ }^{1}$ Respiratory Unit and Cystic Fibrosis Adult Center, Fondazione IRCCS Ca' Granda Ospedale Maggiore Policlinico, \\ Milan; ${ }^{2}$ Department of Pathophysiology and Transplantation, University of Milan, Milan; ${ }^{3}$ Cardio-thoracic Department, \\ ASST Grande Ospedale Metropolitano Niguarda, Milan; ${ }^{4}$ Cystic Fibrosis Regional Centre, Azienda Ospedaliera \\ Universitaria Integrata, Verona; ${ }^{5}$ Health Professions Department Unit, Fondazione IRCCS Ca' Granda Ospedale \\ Maggiore Policlinico, Milan, Italy
}

\begin{abstract}
Inhaled therapy is widely used for treatment of many respiratory disorders. Drug delivery in lungs is dependent on the correct
\end{abstract}

Correspondence: Emilia Privitera, Dipartimento Professioni Sanitarie, Fondazione IRCCS Ca' Granda Ospedale Maggiore Policlinico, Via Sforza 28, 20122 Milano, Italy.

Tel. +39.338.5670909.

E-mail: emilia.privitera@policlinico.mi.it;

Authors' contributions: MS, RG, data acquisition; MS, GB, data analysis, manuscript drafting; MS, EP, ML, data interpretation; MS, EP, ML, ES, FB, manuscript critical revision for important intellectual content; EP, FB, ML, conception and design of the work. All the authors have read and approved the final version of the manuscript and agreed to be accountable for all aspects of the work.

Conflict of interest: The authors declare no conflict of interests

Availability of data and material: The datasets used and/or analyzed during the current study are available from the corresponding author on reasonable request.

Funding: No funds for the present study

Prior abstract publication/presentation: Prior abstract publication and presentation of the present study during the 4th International

Conference on Respiratory Physiotherapy (Treviso, Italy; March 21st 23rd 2019).

Ethics approval and consent to participate: The study was approved by the Ethical Committee Milano Area B (IRB 153 2015). Consent form was signed by all participants. Data were collected and analysed only by researchers, providing full confidentiality and anonymity.

Key words: Aerosol; inhaler technique; practical skills; health care personnel.

Received for publication: 28 July 2020 .

Accepted for publication: 10 November 2020.

${ }^{\circ}$ Copyright: the Author(s), 2021

Licensee PAGEPress, Italy

Monaldi Archives for Chest Disease 2021; 91:1532

doi: 10.4081/monaldi.2021.1532

This article is distributed under the terms of the Creative Commons Attribution Noncommercial License (by-nc 4.0) which permits any noncommercial use, distribution, and reproduction in any medium, provided the original author(s) and source are credited. use of aerosol devices and patients' training is vital for a correct therapy administration. Therefore, is very important to assess the skills of professionals involved in training patients to the correct use of inhaler devices. The aim of this study was to check the practical skills and the theoretical knowledge of health care personnel in our University Hospital in using aerosol therapy and to determine differences among professional figures in the management of inhaler devices. Three hundred and fifteen (315) volunteers including physicians, residents, nurses and respiratory physiotherapists were enrolled; an independent professional, not working in our University Hospital, assessed their theoretical knowledge related to aerosol throughout a questionnaire. Practical skills were assessed through placebo simulation with the devices that participants declared to use frequently with patients. None of the respondents correctly answered all questions evaluating theoretical knowledge on the proper use of aerosol therapy. Respiratory physiotherapists obtained significantly better results with 17.2 (1.3) average points compared to 10.3 (3.7) obtained by doctors, 9.0 (3.0) by nurses and 9.1 (4.5) by residents. Analysing in detail physicians' results, pneumologists showed better theoretical knowledge than other specialists. Concerning the practical skills, about $80 \%$ of those stating they knew how to use metered dose inhalers, made mistakes in the basic steps for proper inhalation technique and over $50 \%$ of respondents were unable to properly simulate placebo administration of dry powder inhalers. Also here, respiratory physiotherapists and pneumologists had significant better performances, when compared to other health professionals. Our data are in line with those published in the literature in other international clinical settings, noting inadequate practical and theoretical knowledge of the available devices for aerosol therapy.

\section{Introduction}

Inhaled aerosols are widely used for treatment of many respiratory diseases, such as asthma and chronic obstructive pulmonary disease (COPD) [1,2]. The primary advantage of inhaled aerosol therapy is treating the lung directly, allowing the use of smaller doses of medicaments, with faster responses and less side effects than with systemic drug delivery. The therapeutic effect of the inhaled aerosol depends on the amount of drug deposition into the lung and is strongly related to a correct inhalation technique (IT) [3]. IT modifies according to the inhaler device used; therefore, device-specific training of patients become vital for optimal drug delivery in the bronchial tree. However, studies have shown that a large proportion of patients is not able to use inhalers correctly, 
omitting or mistaking essential steps that can reduce or completely affect drug deposition. Inadequate IT is mainly observed among elderly and children and is commonly associated with poor disease control, becoming a strong barrier to patients' adherence to treatment [3-7]. Unfortunately, the instructions included into medicaments' package inserts are often not sufficient for patients to learn a correct use of inhalers. Therefore, prescription of aerosol therapy should always be associated with proper information and training of patients to the use of the specific inhaler prescribed [3,8]. Many studies suggested that health care professionals (HCPs) should teach to patients and assess adequate IT and that this training should be repeated and monitored carefully over time $[3,8,9]$. Thus, it is clear that HCPs knowledge of aerosol therapy and its correct technique of administration become crucial in this context. In the last 40 years, many works, performed in different countries, investigated HCPs' skills in aerosol therapy and highlighted a global lack of knowledge and inappropriate IT among health care providers. Surprisingly, a recent systematic review showed that, despite an important educational effort, HCPs abilities in inhaler use have worsened in the last years [8]. Few studies found that among all the health care providers interviewed, respiratory therapists demonstrate better theoretical and practical competency $[10,11]$. To date, only one study was performed in Italy to investigate theoretical knowledge of pediatric health care workers about aerosol therapy, along with oxygen administration and chest physiotherapy, and poor competencies were found in these topics [12]. However, in the literature there are no data on practical skills of Italian HCPs in inhaled therapy. The aim of this study was to assess practical abilities and theoretical knowledge regarding inhaled aerosol therapy of the staff of a large teaching hospital in Milan.

\section{Methods}

\section{Study design and setting}

An observational prospective cross-sectional single centre study was performed among HCPs of Fondazione IRCCS Ca' Granda Ospedale Maggiore Policlinico of Milan (Italy) in all the wards, where usually aerosol therapies are administrated to patients. The following units were considered: Allergology and Immunology, Cardiology, General Surgery, Geriatric, Hepato-biliopancreactic Surgery, High Care Internal Medicine, Intensive Care, Internal Medicine, Occupational Medicine, Pediatric High Care, Pediatric Intensive Care, Pediatric Medium Care, Pediatric Pneumology, Surgical Emergencies, Thoracic Surgery and Vascular Surgery. The study was carried out from February 2015 to August 2016.

\section{Participants}

Participants were volunteer nurses, respiratory physiotherapists (PTs), medical physicians (MDs) and residents working in Fondazione IRCCS Ca' Granda Ospedale Maggiore Policlinico during the study period. Recruitment on a voluntary basis was carried out as follows: all the nurses, MDs, PTs and residents working inside the involved units were asked to participate to the study and volunteers that accepted to participate signed a written informed consent. Inclusion criteria for participants were: age $\geq 18$ years-old and working as nurse, PT, MD or resident in one of the hospital units included in the study. Exclusion criteria were: being previously involved in the preparation of the questionnaire used to assess theoretical knowledge in aerosol inhaled therapy and being previously interviewed to test the questionnaire.

\section{Outcomes and procedures}

The primary outcome of this study was the rate of HCPs demonstrating correct IT. Secondary outcome were the score that HCPs obtained at the questionnaire investigating theoretical knowledge on aerosol therapy and the rate of HCPs answering correctly to each question. Moreover, we assessed whether there was a difference between different HCPs categories.

Practical skills were assessed by direct observation of IT simulation performed by the participants using placebo of the devices that they declared to use in their clinical practice. For every step of the IT, the evaluator assessed whether it was performed correctly, incorrectly or omitted, based on American Association for Respiratory Care recommendations [13]. For every device, steps were divided in critical and not to allow drug delivery into the lung according to Fink et al. [14]. After each simulation with placebo, participants' perceived difficulty in IT was collected using visual analogic scale (VAS), with the two extremities representing "not difficult at all" and "extremely difficult". To analyse VAS scores three value groups were formed: 0-3 (mild difficulty), 4-6 (moderate difficulty) and 7-10 (extremely difficult).

Theoretical knowledge was measured through a questionnaire administered to all participants. The first part of the questionnaire was composed by three preliminary questions inquiring whether participants administrated, prescribed or educated patients to the use of aerosol devices; HCPs that declared not to use inhalers (answered "NO" to all preliminary questions) were excluded from the study. Section A of the questionnaire was divided in 7 parts and collected demographical and educational data of participants and investigated the use of inhalers in clinical practice. Section B of the questionnaire assessed theoretical knowledge on pressurized metered dose inhalers (pMDIs), inhalation chambers (ICs), dry powder inhalers (DPIs) and nebulizers. This section was composed by 21 true/false questions, based on American Association for Respiratory Care recommendations [13]. The questionnaire was prepared by a panel of experts composed by nurses, PTs, MDs and residents; three external senior experts evaluated face validity of the questionnaire and the final revised version of the questionnaire was tested on 20 HCPs. Each correct answer obtained 1 point and each incorrect answer was rated 0 . The maximum score that can be obtained was 21 points.

\section{Statistical analyses}

Categorical variables were described as absolute frequencies and percentages, whereas continuous variables were expressed as mean (standard deviation, SD) or median (interquartile range, IQR). Statistical differences between groups were determined by two sided $\chi^{2}$ test or Student $t$-test for unpaired data. The p-value $\leq 0.05$ was considered statistically significant. For multiple testing, Bonferroni correction was adopted, as appropriate. All analysis were carried out using R-Cran software [15].

\section{Results}

\section{Inhaler devices used in clinical practice}

315 volunteers HCPs were enrolled in this study. Considering all the staff employed at Fondazione IRCCS Ca' Granda Ospedale Maggiore Policlinico di Milano, the coverage rate of enrolled volunteers was $70 \%$ of physicians, $73 \%$ of nurses and $94 \%$ of respiratory therapists. Ten participants were then excluded because they declared not to administrate, prescribe nor edu- 
cate patients to the use of aerosol devices. After answering the questionnaire, IT was assessed using placebo inhalers in 292 cases whereas the remaining 13 hospital workers were excluded from the practical test (Figure $\mathrm{S} 1$ ).

Of the 305 respondents, $185(60.7 \%)$ were female and 120 (39.3\%) were male; the average age was 39.7 (11.4) years. Among the HCPs evaluated in this study 14 were PTs, 150 nurses, 115 MDs and 26 residents (Table 1).

The physician and resident groups were heterogeneous with various medical specialities represented. $90 \%$ of the HCPs interviewed learned IT on-the job and 49\% reading package inserts, while only a few of them acquired information about inhaled therapy during their degree programs. Compared to the other practitioners, a higher percentage of PTs learned how to use inhalers in training courses organized by scientific society (Table 1).

The participants were asked which inhalers they used in their clinical practice among pMDI, pMDI with IC, Breezhaler ${ }^{\circledR}$, Handihaler ${ }^{\circledR}$, Diskus ${ }^{\circledR}$, Turbohaler $^{\circledR}$, Twisthaler ${ }^{\circledR}$, Genuair $^{\circledR}$ and Respimat ${ }^{\circledR}$. None declared to use all 9 devices considered in this study and the median number of inhalers known and used was 2 (1-3). Among all HCPs, PTs showed a median number of known devices significantly higher than the others [5 (3-6) for PTs $v s 2$ (1-3) for nurses and residents and 2 (1-4) for physicians]. Among physicians, pneumologists knew and used a higher number of devices as compared to other specialists (Tables S1 and S2). pMDI was the most employed inhaler (92\%), followed by Diskus $^{\circledR}(53 \%)$ and Handihaler ${ }^{\circledR}(38 \%)$, whereas Twisthaler ${ }^{\circledR}$ was the less known and used device $(6 \%)$. Only $28 \%$ of participants used IC with pMDI. PTs showed a significantly higher percentage of use of spacer $(100 \%)$, compared to other HCPs $(20 \%$ of nurses; $33 \%$ of physicians; $11 \%$ of residents) and also a significant higher use of Breezhaler ${ }^{\circledR}$ and Diskus ${ }^{\circledR}$ (Table S1). Comparing nurses working inside the Pneumology Unit with nurses working in other hospital units, no significant difference was found in the percentage of inhaler used, except for Breezhaler ${ }^{\circledR}$ (33\% of nurses working in the Pneumology Unit $v s$ $11 \%$ of nurses working in all the other wards).

Among physicians, we found that the percentage of pneumologists attesting the use of many aerosol devices is significantly higher than other specialists, except for pMDI and Twisthaler ${ }^{\circledR}$; pMDI is quite diffuse also among other physiscians, whereas Twisthaler ${ }^{\circledR}$ is not strongly used also by pneumologists (Table S2).

The personal and familiar use of the nine aerosol devices was also assessed and again pMDI and Diskus ${ }^{\circledR}$ appeared to be the most prescribed devices. No differences were found in the personal and familiar use of aerosols among the different HCPs categories (Table S1).

\section{Theoretical knowledge in aerosol therapy}

None of the 305 participants answered correctly to all the questions assessing theoretical knowledge in aerosol therapy. The mean score was 9.9 (3.8) points. PTs obtained a mean score significantly higher than the other HCPs, with 17.2 (1.3) mean points. PTs demonstrated a better knowledge than other health care workers, mainly regarding the use of IC and the respiratory pattern patients should use during inhalation (Table 2).

Among MDs, pneumologists demonstrated a significant better theoretical knowledge, with a mean score of 14.7 (2.0) compared to 9.6 (3.4) obtained by all the other specialists (Table S3). No significant difference was found in theoretical knowledge assessed by the questionnaire among nurses working inside the Pneumology Unit and nurses working in other hospital wards, except for the question investigating the importance of using a mouthpiece instead of a face mask when performing nebulization with a cooperative patient (Table S3).

Questions dealing with the respiratory pattern during inhalation of pMDI and DPI (questions 2, 11 and 13), collected the greatest number of errors, with a global percentage of correct answers lower than $20 \%$ (Table 2).

\section{Practical skills in aerosol therapy}

Abilities in inhaled therapy were assessed by a simulation with a placebo of the devices each participant declared to use in its clinical practice. Table 3 shows the results obtained in practical simulation expressed as percentage of performances without errors in critical steps for correct IT and mean number of correct steps for each device.

During the evaluation of the use of pMDI two possible techniques were considered; the closed mouth technique contemplated to place the mouthpiece of the canister fully into the mouth, holding the inhaler in a mouthpiece-down position and closing lips around the mouthpiece. The alternative, called open mouth technique, was to position the mouthpiece $4 \mathrm{~cm}$ from open mouth. Two hundred and forty-eight (248) simulations were recorded as closed mouth technique, whereas 37 simulations with pMDI alone used open mouth technique.

Globally, $73 \%$ of subjects that affirmed to know how to use pMDI and more than $50 \%$ of respondents that affirmed to know how to use DPI made critical mistakes in IT simulation. The percentage of correct IT for pMDI + IC with facial mask was $67 \%$; it's important to highlight that, among the 8 participants that simulated the use of pMDI + IC with facial mask, 3 had a relative that used this aerosol device and 5 worked in pediatric units. PTs showed significantly better performances than all the other practitioners in the use of Diskus ${ }^{\circledR}$, with $69 \%$ of adequate simulation, compared to $12 \%$ of nurses, $29 \%$ of physicians and $7 \%$ of residents. Moreover, a significantly higher percentage of PTs demonstrated correct inhaler technique with pMDI alone or combined with IC, when compared with nurses and MDs. Consistently with these results, we observed that the mean number of correct steps in simulation with pMDI, pMDI + IC, and Diskus ${ }^{\circledR}$ was significantly higher for PTs than for all other health care workers (Table 3 ).

Among physicians, pneumologists' demonstrations were significantly better for pMDI, Handihaler ${ }^{\circledR}$, Diskus ${ }^{\circledR}$ and Turbohaler ${ }^{\circledR}$. In accordance with what already observed for theoretical knowledge, no significant difference was found in practical abilities assed by simulation with placebo devices among nurses working inside the Pneumology Unit and nurses working in other hospital units (Table S4).

The most common erroneous or missed steps in pMDI simulation were "inhale slowly and deeply and hold the breath for 10 seconds or as long as possible" and "wait a minute if another puff is needed". Similarly, in simulation with pMDI + IC over $50 \%$ of errors or omissions were in holding the breath and waiting a minute before taking the second puff. Errors and omissions were quite lower for inhalation with pMDI + IC + facial mask. For DPIs the most erroneous step is holding breath after inhalation and in the case of single-dose DPI also repeating the inhalation. In the simulation with soft mist performing a slow and deep inhalation while activating the device was the most missed or failed step (Figure S2).

In order to assess whether the performances obtained at the IT simulation were linked with participants' age, time from graduation, theoretical knowledge measured with the questionnaire and number of devices used in the current clinical practice, we divided performances for each device in good (no error/omission in critical 
Table 1. Demographic data, working information and background of participants and of the different groups of healthcare professionals.

\begin{tabular}{|c|c|c|c|c|c|}
\hline & $\begin{array}{c}\text { Total } \\
(n=305)\end{array}$ & $\begin{array}{c}\text { Respiratory } \\
\text { physiotherapists } \\
(\mathrm{n}=14)\end{array}$ & $\begin{array}{l}\text { Nurses } \\
(\mathrm{n}=150)\end{array}$ & $\begin{array}{c}\text { Physicians } \\
(\mathrm{n}=115)\end{array}$ & $\begin{array}{c}\text { Residents } \\
(n=26)\end{array}$ \\
\hline Age, years [mean (SD)] & $39.7(11.4)$ & $39.7(10.8)$ & $37.3(9.9)$ & $45.4(11.5)$ & $28.7(2.3)$ \\
\hline Female, n (\%) & $185(60.7)$ & $12(86)$ & $99(66)$ & $62(54)$ & $12(46)$ \\
\hline Male, n (\%) & $120(39.3)$ & $2(14)$ & $51(34)$ & $53(46)$ & $14(54)$ \\
\hline Years from graduation, mean (SD) & $15.2(11.1)$ & $16.6(11.1)$ & $13.5(9.9)$ & $19.8(11.3)$ & $3.6(1.6)$ \\
\hline Administrate inhaled therapy, n (\%) & $275(90)$ & $14(100)$ & $99(66)$ & $92(80)$ & $21(81)$ \\
\hline Train patients to use inhaled therapy, n (\%) & $221(72)$ & $14(100)$ & $124(83)$ & $72(63)$ & $11(42)$ \\
\hline Prescribe inhaled therapy, n (\%) & $135(44)$ & $0(0)$ & $3(2)$ & $109(78)$ & $23(88)$ \\
\hline \multicolumn{6}{|l|}{ Working unit } \\
\hline Allergology and Immunology Unit, n (\%) & $5(1)$ & - & - & $5(4)$ & - \\
\hline Cardiology Unit, n (\%) & $39(13)$ & - & $17(11)$ & $18(16)$ & $4(15)$ \\
\hline General Surgical Unit, n (\%) & $13(4)$ & - & $11(8)$ & - & $2(8)$ \\
\hline Geriatric Unit, n (\%) & $15(5)$ & - & $8(5)$ & $5(4)$ & $2(8)$ \\
\hline Hepato-biliopancreactic Surgery Unit, n (\%) & $14(5)$ & - & $6(4)$ & $5(4)$ & $3(11)$ \\
\hline High Care Internal Medicine Unit, n (\%) & $23(7)$ & - & $14(9)$ & $8(7)$ & $1(4)$ \\
\hline Intensive Care Unit, n (\%) & $39(12)$ & - & $21(14)$ & $14(12)$ & $4(15)$ \\
\hline Internal Medicine Unit, n (\%) & $23(7)$ & - & $14(9)$ & $7(6)$ & $2(8)$ \\
\hline Occupational Medicine Unit, n (\%) & $6(2)$ & - & $2(1)$ & $4(3)$ & - \\
\hline Pediatric High Care Unit, n (\%) & $14(5)$ & - & $10(7)$ & $4(3)$ & - \\
\hline Pediatric Intensive Care Unit, n (\%) & $7(3)$ & 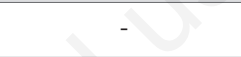 & $5(3)$ & $2(2)$ & - \\
\hline Pediatric Medium Care Unit, n (\%) & $21(7)$ & - & $13(9)$ & $8(7)$ & - \\
\hline Pediatric Unit, n (\%) & $10(3)$ & $6(43)$ & $1(1)$ & $3(3)$ & - \\
\hline Pneumology Unit, n (\%) & $35(11)$ & $7(50)$ & $12(8)$ & $14(12)$ & $2(8)$ \\
\hline Surgical Emergency Unit, n (\%) & $11(4)$ & - & 7 (5\%ù) & $4(4)$ & $11(4)$ \\
\hline Thoracic Surgery Unit, n (\%) & $25(8)$ & $1(7)$ & $9(6)$ & $9(8)$ & $6(23)$ \\
\hline Vascular Surgery Unit, n (\%) & $5(2)$ & - & $5(4)$ & - & - \\
\hline \multicolumn{6}{|l|}{ Medical speciality } \\
\hline Allergology, n (\%) & - & - & - & $5(4)$ & - \\
\hline Anesthesiology and Intensive Care, n (\%) & - & - & - & $15(13)$ & $4(15)$ \\
\hline Cardiology, n (\%) & - & - & - & $19(17)$ & $2(8)$ \\
\hline Endocrinology, n (\%) & - & - & - & $1(1)$ & - \\
\hline General Surgery, n (\%) & - & - & - & $14(12)$ & $7(27)$ \\
\hline Geriatric Medicine, n (\%) & - & - & - & $4(3)$ & $3(11)$ \\
\hline Internal Medicine, n (\%) & - & - & - & $14(12)$ & $3(11)$ \\
\hline Occupational Medicine, $\mathrm{n}(\%)$ & - & - & - & $3(3)$ & - \\
\hline Pediatrics, n (\%) & - & - & - & $14(12)$ & - \\
\hline Physical Medicine and Rehabilitation, n (\%) & - & - & - & - & $1(4)$ \\
\hline Pneumology, n (\%) & - & - & - & $16(14)$ & $2(8)$ \\
\hline Thoracic Surgery, n (\%) & - & - & - & $4(3)$ & $4(15)$ \\
\hline Vascular Surgery, n (\%) & - & - & - & $5(4)$ & - \\
\hline \multicolumn{6}{|l|}{ Inhaler Training } \\
\hline BSc degree program, n (\%) & $131(16)$ & $0(0)$ & $96(64)$ & $29(25)$ & $6(23)$ \\
\hline Post-graduate degree program, n (\%) & $49(16)$ & $7(50)$ & $5(3)$ & $25(22)$ & $12(46)$ \\
\hline Congress/courses organized by scientific society, n (\%) & $44(14)$ & $8(57)$ & $12(8)$ & $22(19)$ & $2(8)$ \\
\hline Congress/courses organized by pharmaceutical society, n (\%) & $42(14)$ & $6(43)$ & $7(5)$ & $26(23)$ & $3(11)$ \\
\hline On-the-job training, n (\%) & $275(90)$ & $14(100)$ & $140(93)$ & $100(87)$ & $21(81)$ \\
\hline Package insert, n (\%) & $149(49)$ & $6(43)$ & $89(59)$ & $43(37)$ & $11(42)$ \\
\hline Scientific articles, n (\%) & $42(14)$ & $9(64)$ & $9(6)$ & $22(19)$ & $2(8)$ \\
\hline Web tutorial, n (\%) & $14(5)$ & $2(14)$ & $7(5)$ & $3(3)$ & $2(8)$ \\
\hline
\end{tabular}


steps of IT) and bad (at least one error/omission in a critical step of IT) and analyzed these variables in each group. We found that for all devices, except for pMDI + IC and Turbohaler ${ }^{\circledR}$, health care workers showing better practical abilities, use and know a signifi- cant higher number of inhalers and obtained significantly higher scores at the questionnaire assessing theoretical knowledge. No differences were found in age and time from graduation among practitioners making good and bad simulation of inhalation (Table 4).

Table 2. Theoretical knowledge of participants on inhaled therapy measured by the questionnaire. For this multiple testing Bonferroni correction was used, as appropriate.

\begin{tabular}{|c|c|c|c|c|c|}
\hline Theoretical knowledge & $\begin{array}{c}\text { Total } \\
(n=305)\end{array}$ & $\begin{array}{l}\text { Respiratory } \\
\text { physiotherapists } \\
(n=14)\end{array}$ & $\begin{array}{l}\text { Nurses } \\
(\mathrm{n}=150)\end{array}$ & $\begin{array}{l}\text { Physicians } \\
(\mathrm{n}=115)\end{array}$ & $\begin{array}{l}\text { Residents } \\
(n=26)\end{array}$ \\
\hline Total score, mean (SD) & $9.9(3.8)$ & $17.2(1.3)^{\mathrm{NM} \mathrm{R}}$ & $9.0(3.0)$ & $10.3(3.7)$ & $9.1(4.5)$ \\
\hline \multicolumn{6}{|l|}{ pMIDI, n correct $(\%)$} \\
\hline $\begin{array}{l}\text { 1- It is important to shake the pMDI canister before every puff } \\
\text { (True) }\end{array}$ & $200(66)$ & $13(93)^{\mathrm{R}}$ & $102(68)^{\mathrm{R}}$ & $75(65)^{\mathrm{R}}$ & $10(39)$ \\
\hline $\begin{array}{l}\text { 2- When inhaling a puff from a pMDI you should breathe deeply } \\
\text { and fast (False) }\end{array}$ & $55(18)$ & $8(57)^{\mathrm{NMR}}$ & $22(15)$ & $24(21)$ & $1(4)$ \\
\hline $\begin{array}{l}\text { 3- It is not necessary to rinse the mouth after inhalation of a } \\
\text { corticorsteroid (False) }\end{array}$ & $169(55)$ & $12(86)^{\mathrm{N}}$ & $69(46)$ & $73(63)^{\mathrm{N}}$ & $15(58)$ \\
\hline $\begin{array}{l}\text { 4- When using a new canister or a canister that has not been } \\
\text { used for some days, it is not necessary to release one or more } \\
\text { sprays into the air (False) }\end{array}$ & $191(63)$ & $9(64)$ & $88(59)$ & $79(69)$ & $15(58)$ \\
\hline \multicolumn{6}{|l|}{ IC, $\mathrm{n}$ correct $(\%)$} \\
\hline $\begin{array}{l}\text { 5- Using IC with pMDI reduces oropharyngeal deposition } \\
\text { of the drug (True) }\end{array}$ & $137(45)$ & $13(93)^{\mathrm{NM}}$ & $43(29)$ & $65(57)^{\mathrm{N}}$ & $16(62)^{\mathrm{N}}$ \\
\hline $\begin{array}{l}\text { 6- If multiple puffs should be administrated, all puffs should be } \\
\text { fired into the device before inhalation (False) }\end{array}$ & $135(44)$ & $14(100)^{N M R}$ & $55(37)$ & $56(49)$ & $10(39)$ \\
\hline $\begin{array}{l}\text { 7- It is possible to scrub the inner part of the IC to clean it } \\
\text { properly (False) }\end{array}$ & $75(25)$ & $10(71)^{\mathrm{NM}}$ & $23(15)$ & $34(30)^{\mathrm{N}}$ & $8(31)$ \\
\hline $\begin{array}{l}\text { 8- Inhalation could be performed hours after drug nebulization } \\
\text { into the spacer (False) }\end{array}$ & $210(69)$ & $14(100)^{N R}$ & $88(59)$ & $91(79)^{\mathrm{N}}$ & $17(65)$ \\
\hline $\begin{array}{l}\text { 9- Deposition of a white powder into the holding chamber } \\
\text { is normal (True) }\end{array}$ & $99(32)$ & $13(93)^{\mathrm{N} M ~ R}$ & $44(29)$ & $37(32)$ & $5(19)$ \\
\hline $\begin{array}{l}\text { 10- Depending on the material, IC can have electrostatic } \\
\text { charge (True) }\end{array}$ & $81(27)$ & $13(93)^{\mathrm{NM} R}$ & $16(11)$ & $44(38)^{N}$ & $8(31)^{\mathrm{N}}$ \\
\hline \multicolumn{6}{|l|}{ DPIs, n correct $(\%)$} \\
\hline $\begin{array}{l}\text { 11- When using a DPI is important to breathe deeply and slowly } \\
\text { (False) }\end{array}$ & $35(11)$ & $5(36)^{\mathrm{N}}$ & $10(7)$ & $14(12)$ & $6(23)^{\mathrm{N}}$ \\
\hline $\begin{array}{l}\text { 12- When using a DPI is important not to exhale into the device } \\
\text { (True) }\end{array}$ & $217(71)$ & $12(86)$ & $107(71)$ & $79(69)$ & $19(73)$ \\
\hline $\begin{array}{l}\text { 13- It is possible to use a DPI when the inspiratory flow peak } \\
\text { of the patient is less than } 30 \mathrm{l} / \mathrm{min} \text { (False) }\end{array}$ & $56(18)$ & $13(93)^{\mathrm{NM} R}$ & $8(5)$ & $28(24)^{N}$ & $7(27)^{N}$ \\
\hline $\begin{array}{l}\text { 14- When using a DPI it is not important to hold the breath } \\
\text { at the end of inspiration (False) }\end{array}$ & $165(54)$ & $11(79)$ & $73(49)$ & $66(57)$ & $15(58)$ \\
\hline $\begin{array}{l}\text { 15- Strong reduction in vital capacity can affect the amount } \\
\text { of drug delivered to the lung (True) }\end{array}$ & $203(67)$ & $13(93)$ & $94(63)$ & $78(68)$ & $8(69)$ \\
\hline \multicolumn{6}{|l|}{ Nebulizer, n correct (\%) } \\
\hline $\begin{array}{l}\text { 16- It is not important how much time occurs between the } \\
\text { preparation of the medication and nebulization (False) }\end{array}$ & $252(83)$ & $13(93)$ & $122(81)$ & $96(84)$ & $21(81)$ \\
\hline $\begin{array}{l}\text { 17- It is correct to use a humidifier during aerosol nebulization } \\
\text { (False) }\end{array}$ & $120(39)$ & $13(93)^{\mathrm{NM} R}$ & $71(47)^{M ~ R ~}$ & $33(29)$ & $3(12)$ \\
\hline $\begin{array}{l}\text { 18- With cooperative patients, it is correct to use mouthpiece } \\
\text { instead of face mask to deliver aerosol (True) }\end{array}$ & $196(64)$ & $14(100)^{\mathrm{NM} \mathrm{R}}$ & $102(68)$ & $67(58)$ & $13(50)$ \\
\hline $\begin{array}{l}\text { 19- Using a jet nebulizer with compressed gas flow, } \\
\text { it is necessary to use a maximum gas flow of } 5 \mathrm{l} / \mathrm{min} \text { (False) }\end{array}$ & $119(39)$ & $11(79)^{\mathrm{NM}}$ & $59(39)$ & $39(34)$ & $10(39)$ \\
\hline $\begin{array}{l}\text { 20- When preparing the medication for nebulization } \\
\text { it is important to consider dead volume of the jet nebulizer (True) }\end{array}$ & $165(54)$ & $11(79)$ & $80(53)$ & $60(52)$ & $14(54)$ \\
\hline $\begin{array}{l}\text { 21- When using a face mask with a jet nebulizer it is necessary } \\
\text { to inhale through the mouth (True) }\end{array}$ & $131(43)$ & $6(43)$ & $70(47)$ & $49(43)$ & $6(23)$ \\
\hline
\end{tabular}
to inhale through the mouth (True)

N, significant difference with the nurses group; M, significant difference with the physicians group; R, Significant difference with the residents group; IC, inhalation chamber; DPI, dry powder inhaler; pMDI, pressurized metered dose inhalers. 
Perceived difficulty in IT was assessed after each simulation using VAS; in Table 4 the percentage of participants rating mild (VAS 0 to 3), moderate (VAS 4 to 6) or severe (VAS 7 to 10) difficulty during inhalation, among those who showed good (no error/omission in critical steps of IT) and bad (at least one error/omission in a critical step of IT) IT, are represented. For the majority of the devices, respondents reported low levels of perceived difficulty during simulation, although, for many of them, IT demonstrated was not correct.

\section{Discussion}

Health care practitioners play a critical role in patients' education and training in the use of aerosol devices $[16,17]$. To date, literature shows that nurses, pharmacists, physicians, residents, medicine students and PTs, working in many different health structures, have inadequate knowledge on inhaler devices for aerosol therapy [8]. While theoretical knowledge of Italian HCPs on aerosol therapy was previously evaluated by Esposito et al. [12], this is the first study that investigates, in Italy, the practical abilities of HCPs on aerosol therapy. Proper practical skills are crucial when educating patients to the appropriate inhaler technique, which allows optimal delivery of medications and can enhance patient adherence to the therapy.
Our study confirms previous finding, highlighting a global lack of knowledge on inhaled therapy among HCPs and extending it to new aerosol devices.

Among the 9 inhalers tested in practical simulation, only pMDI + IC + facial mask showed a percentage of correct performances overcoming $50 \%$. Surprisingly, many errors in critical steps for correct drug deposition were made also in practical simulation with placebo of devices in current usage from many years, as pMDI, and with easy to use inhalers, such as Diskus ${ }^{\circledR}$, indicating that the gap of knowledge was not restricted to most recent aerosol devices.

Moreover, only $28 \%$ of participants used IC with pMDI in their clinical practice, although spacers were shown to reduce oropharingeal deposition and improve effectiveness of aerosol therapy [5].

Interestingly, participants tended to be quite confident on their own inhalation technique, highlighting a misevaluation of their personal skills and of the education need in this domain.

Practitioners enrolled in this study not only did not show correct inhalation technique, but demonstrated a poor understanding and knowledge of aerosol therapy principles and theoretic basis of use. Differences in knowledge and practical abilities were not found between subjects that declared to teach to patients how to use inhalers and those who did not. This aspect is fundamental, because many works previously demonstrated the importance to assess and train patients to a correct IT and the critical role that HCPs play in this context [16,17]. Indeed, we found that HCPs

Table 3. Practical skills in inhaled therapy measured by simulation with placebo devices. Results are represented in terms of number of participants that performed a demonstration without errors in the critical steps for drug deposition into the lung and in terms of mean (SD) number of correct steps for each device tested. For this multiple testing Bonferroni correction was used, as appropriate.

\begin{tabular}{|c|c|c|c|c|c|}
\hline Practical skills, $n$ and $\%$ of correct simulation & Total & $\begin{array}{c}\text { Respiratory } \\
\text { physiotherapists }\end{array}$ & Nurses & Physicians & Residents \\
\hline pMDI open mouth technique, n (\%) & $10 / 37(27)$ & $3 / 4(75)$ & $3 / 19(16)$ & $4 / 11(36)$ & $0 / 3(0)$ \\
\hline pMDI closed mouth technique, n (\%) & $36 / 248(15)$ & $4 / 7(57)^{\mathrm{NM}}$ & $13 / 120(11)$ & $16 / 98(16)$ & $3 / 23(13)$ \\
\hline pMDI + IC, n (\%) & $26 / 85(31)$ & $10 / 14(71)^{\mathrm{NM}}$ & $7 / 29(24)$ & $9 / 39(23)$ & $0 / 3(0)$ \\
\hline pMDI + IC + facial mask, n (\%) & $8 / 12(67)$ & $4 / 4(100)$ & $2 / 4(50)$ & $2 / 4(50)$ & - \\
\hline Breezhaler®, n (\%) & $18 / 54(33)$ & $7 / 9(78)^{\mathrm{N}}$ & $1 / 19(5)$ & $9 / 22(41)^{N}$ & $1 / 4(25)$ \\
\hline Handihaler®, n (\%) & 24/117 (21) & $7 / 9(78)^{N}$ & $4 / 72(5)$ & $11 / 28(39)^{\mathrm{N}}$ & 2/8 (25) \\
\hline Diskus@, n (\%) & $37 / 162(23)$ & $9 / 13(69)^{\mathrm{NM} \mathrm{R}}$ & $9 / 73(12)$ & $18 / 62(29)$ & $1 / 14(7 \%)$ \\
\hline Turbohaler@, n (\%) & $19 / 41(46)$ & $3 / 6(50)$ & $1 / 11(9)$ & $14 / 23(61)^{\mathrm{N}}$ & $1 / 1(100)$ \\
\hline Twisthaler®, n (\%) & $4 / 18(22)$ & $1 / 1(100)^{\mathrm{N}}$ & $0 / 6(0)$ & 2/9 (22) & $1 / 2(50)$ \\
\hline Genuair ${ }^{\circledR}, \mathrm{n}(\%)$ & $15 / 36(42)$ & $1 / 2(50)$ & $0 / 8(0)$ & $11 / 20(55)^{\mathrm{N}}$ & $3 / 6(50)$ \\
\hline Respimat $®, \mathrm{n}(\%)$ & $12 / 39(31)$ & $3 / 5(60)^{\mathrm{N}}$ & $0 / 10(0)$ & $8 / 21(38)$ & $1 / 3(33)$ \\
\hline \multicolumn{6}{|l|}{ Practical skills, mean of correct steps } \\
\hline pMDI open mouth technique (10 steps), mean (SD) & $6(2)$ & $9(1)^{\mathrm{N} R}$ & $5(2)$ & $7(2)$ & $4(1)$ \\
\hline pMDI closed mouth technique (10 steps), mean (SD) & $5(2)$ & $8(1)^{\mathrm{NMR}}$ & $5(2)$ & $5(2)$ & $5(2)$ \\
\hline pMDI + IC (10 steps), mean (SD) & $8(3)$ & $11(1)^{\mathrm{NMR}}$ & $7(3)$ & $8(2)$ & $6(3)$ \\
\hline pMDI + IC + facial mask (11 steps), mean (SD) & $9(1)$ & $10(0)$ & $9(1)$ & $9(2)$ & - \\
\hline Breezhaler® (16 steps), mean (SD) & $13(3)$ & $16(0)^{\mathrm{N}}$ & $12(3)$ & $14(2)^{N}$ & $12(5)$ \\
\hline Handihaler® (15 steps), mean (SD) & $11(3)$ & $14(2)^{N}$ & $10(3)$ & $12(3)^{\mathrm{N}}$ & $11(3)$ \\
\hline Diskus® (9 steps), mean (SD) & $6(2)$ & $8(1)^{\mathrm{NM} R}$ & $6(2)$ & $6(2)$ & $6(2)$ \\
\hline Turbohaler® (9 steps), mean (SD) & $7(2)$ & $8(1)^{N}$ & $6(2)$ & $8(2)^{N}$ & $9(0)$ \\
\hline Twisthaler® (10 steps), mean (SD) & $8(2)$ & $10(0)$ & $8(1)$ & $7(3)$ & $10(1)$ \\
\hline Genuair ${ }^{\circledR}$ (13 steps), mean (SD) & $9(4)$ & $12(1)^{\mathrm{N}}$ & $6(4)$ & $10(4)$ & $9(5)$ \\
\hline Respimat@ (10 steps), mean (SD) & $7(3)$ & $9(2)$ & $7(1)$ & $7(3)$ & $6(5)$ \\
\hline
\end{tabular}

$\mathrm{N}$, significant difference with the nurses group; M, significant difference with the physicians group; R, Significant difference with the residents group; IC, inhalation chamber; DPI, dry powder inhaler; pMDI, pressurized metered dose inhalers. 
made, during the simulation of inhalation, the same errors reported from patients $[3,18]$.

We observed that the number of devices that respondents declared to know and use is linked with their practical abilities. Thus, it is not strange that pneumologists, who used more aerosol devices and know also the newest such as soft mist, showed better knowledge and skills than other physicians. Surprisingly, nurses working inside the Pneumology Unit, did not showed better practical abilities in aerosol than nurses working in other hospital units. This could reflect the importance of structured training on inhaler use and not only on the job training.

As other works previously demonstrated [10,11], PTs are the group of health care practitioners with more competencies in aerosol therapy. They used and knew a higher number of devices, had better knowledge of their mechanism of functioning and showed better practical abilities during the simulation of the inhalation technique with many of the tested devices. This result could be linked to the specific nature of PTs tasks in their clinical practice. Moreover, PTs obtained a formal education in aerosol therapy not during their BSc course, but mainly in post-graduate courses, in specific training held by scientific society and reading scientific articles.
Consistently, a previous national survey demonstrated the key role of PTs in the aerosol delivery practice in cystic fibrosis. Gambazza et al. found that PTs are involved in all aspects of aerosol therapy, from dilution and mixing of drugs to patient and caregiver education [19].

Considering the low number of PTs employed in our hospital and the high number of hospital units prescribing inhaled therapy for patients, it seems very important to involve this professional figure, with a specific post-graduate training in pulmonary rehabilitation, in the process of education of other HCPs to ensure optimal delivery of aerosol therapy to all patients from all the professionals involved in their care.

One limitation of this study is the low number of PTs included, compared to other categories of health care providers. Nevertheless, it is important to highlight that almost the totality of PTs working in Fondazione IRCCS Ca' Granda Ospedale Maggiore Policlinico of Milan was enrolled in this study. This large difference between the number of respiratory physiotherapists employed compared to the number of nurses and physicians is representative of the actual situation in many Italian acute hospitals. Further work should be done to verify HCPs practical abilities about inhaled therapy in other Italian hospitals.

Table 4. Health care providers showing better practical abilities (good inhalation technique, no errors or omission in the critical steps for drug deposition into the lung), use and know a significant higher number of inhalers and obtained significantly higher scores at the questionnaire assessing theoretical knowledge as compared to participants showing poor practical skills (bad inhalation technique, errors or omissions in at least one critical step for drug delivery into the lung).

\begin{tabular}{|c|c|c|c|c|c|c|c|c|}
\hline \multirow[t]{2}{*}{ Practical simulation } & \multirow{2}{*}{$\begin{array}{l}\text { Devices } \\
\text { used, } \\
\text { median } \\
\text { (IQR) }\end{array}$} & \multirow{2}{*}{$\begin{array}{l}\text { Theoretical } \\
\text { knowledge, } \\
\text { mean } \\
\text { (SD) }\end{array}$} & \multirow{2}{*}{$\begin{array}{l}\text { Age, } \\
\text { years } \\
\text { [mean } \\
\text { (SD)] }\end{array}$} & \multirow{2}{*}{$\begin{array}{l}\text { Years } \\
\text { from } \\
\text { graduation, } \\
\text { mean } \\
\text { (SD) }\end{array}$} & \multicolumn{4}{|c|}{ Visual analogic scale, $\mathbf{n}(\%)$} \\
\hline & & & & & $0-3$ & 4-6 & $7-10$ & $\begin{array}{c}\text { Missing } \\
\text { data, } n\end{array}$ \\
\hline pMDI open mouth Good inhalation technique $(\mathrm{n}=10)$ & $7(4-8)^{*}$ & $14.3(4.1)^{*}$ & $38.1(12.6)$ & $14.8(12.2)$ & $6(60)$ & $2(20)$ & $2(20)$ & - \\
\hline pMDI open mouth Bad inhalation technique (n=27) & $1(1-3)$ & $7.6(4.7)$ & $41.4(11.3)$ & $17.1(11.4)$ & $17(63)$ & $5(18)$ & $5(18)$ & - \\
\hline $\begin{array}{l}\text { pMDI closed mouth } \\
\text { Good inhalation technique }(n=36)\end{array}$ & $3(2-4)^{*}$ & $12.4(5.0)^{*}$ & $38.9(10.0)$ & $16.2(10.2)$ & $32(94)$ & $2(6)$ & $0(0)$ & 2 \\
\hline $\begin{array}{l}\text { pMDI closed mouth } \\
\text { Bad inhalation technique }(n=212)\end{array}$ & $2(1-3)$ & $9.1(3.1)$ & $41.0(11.4)$ & $16.3(10.9)$ & $172(83 \%)$ & $31(15)$ & $4(2)$ & 5 \\
\hline pMDI + IC Good inhalation technique $(\mathrm{n}=26)$ & $4(3-7)$ & $14.2(3.0)^{*}$ & $42.1(10.6)$ & $17.9(10.5)$ & $23(96)$ & $1(4)$ & $0(0)$ & 2 \\
\hline pMDI + IC Bad inhalation technique $(\mathrm{n}=59)$ & $3(2-6)$ & $12.4(3.2)$ & $38.6(12.5)$ & $14.1(11.7)$ & $46(79)$ & $9(16)$ & $3(5)$ & 1 \\
\hline pMDI + IC + facial mask Good inhalation technique $(\mathrm{n}=8)$ & $4(3-4)$ & $15.3(2.6)^{*}$ & $45.8(7.0)$ & $22.4(8.1)$ & $4(100)$ & $0(0)$ & $0(0)$ & 4 \\
\hline pMDI + IC + facial mask Bad inhalation technique $(n=4)$ & $2(2-2)$ & $11.5(4.4)$ & $38.3(6.8)$ & $16.0(8.9)$ & $2(100)$ & $0(0)$ & $0(0)$ & 2 \\
\hline Breezhaler® Good inhalation technique $(\mathrm{n}=18)$ & $7(6-8) *$ & $15.8(2.0)^{*}$ & $39.6(11.1)$ & $14.6(10.9)$ & $16(89)$ & $2(11)$ & $0(0)$ & - \\
\hline Breezhaler@ Bad inhalation technique $(\mathrm{n}=36)$ & $5(4-7)$ & $11.1(3.3)$ & $36.4(11.9)$ & $11.8(11.0)$ & $27(75)$ & $6(17)$ & $3(8)$ & - \\
\hline Handihaler ${ }^{\circledR}$ Good inhalation technique ( $\left.\mathrm{n}=24\right)$ & $7(5-8) *$ & $14.9(3.1)^{*}$ & $34.7(8.3)$ & $10.2(8.2)$ & $22(92)$ & $1(4)$ & $1(4)$ & - \\
\hline Handihaler $®$ Bad inhalation technique ( $\mathrm{n}=93$ ) & $3(3-4)$ & $9.5(3.2)$ & $35.2(8.7)$ & $11.0(8.5)$ & $59(66)$ & $20(22)$ & $10(11)$ & 4 \\
\hline Diskus ${ }^{\circledR}$ Good inhalation technique $(\mathrm{n}=37)$ & $6(3-8) *$ & $13.9(3.5)^{*}$ & $39.2(11.0)$ & $14.4(10.8)$ & $29(83)$ & $4(11)$ & $2(6)$ & 2 \\
\hline Diskus ${ }^{\circledR}$ Bad inhalation technique $(\mathrm{n}=125)$ & $3(2-4)$ & $10.2(3.3)$ & $37.8(11.0)$ & $13.3(10.6)$ & $60(50)$ & $35(29)$ & $25(21)$ & 5 \\
\hline Turbohaler@ Good inhalation technique $(\mathrm{n}=19)$ & $8(7-8) *$ & $14.9(2.2)^{*}$ & $38.5(12.2)$ & $13.4(12.2)$ & $17(89)$ & $1(5)$ & $1(5)$ & - \\
\hline Turbohaler@ Bad inhalation technique ( $\mathrm{n}=22$ ) & $6(5-7)$ & $12.0(2.9)$ & $35.5(10.5)$ & $10.9(8.8)$ & $11(50)$ & $8(36)$ & $3(14)$ & - \\
\hline Twisthaler ${ }^{\circledR}$ Good inhalation technique $(\mathrm{n}=4)$ & $8(8-8) *$ & $16.0(2.9)$ & $34.3(3.9)$ & $9.5(4.8)$ & $4(100)$ & $0(0)$ & $0(0)$ & - \\
\hline Twisthaler® Bad inhalation technique $(\mathrm{n}=14)$ & $6(5-8)$ & $11.9(2.7)$ & $39.1(15.4)$ & $13.1(12.1)$ & $7(58)$ & $5(42)$ & $0(0)$ & 2 \\
\hline Genuair® Good inhalation technique $(\mathrm{n}=15)$ & $8(7-8) *$ & $14.9(2.0)^{*}$ & $35.5(11.7)$ & $10.9(11.6)$ & $11(79)$ & $0(0)$ & $3(21)$ & 1 \\
\hline Genuair ${ }^{\circledR}$ Bad inhalation technique ( $\left.\mathrm{n}=21\right)$ & $5(4-8)$ & $10.4(3.2)$ & $34.4(10.4)$ & $9.9(8.9)$ & $14(78)$ & $3(17)$ & $1(6)$ & 3 \\
\hline Respimat ${ }^{\circledR}$ Good inhalation technique $(\mathrm{n}=12)$ & $8(7-8)^{*}$ & $15.0(2.1)^{*}$ & $36.6(9.0)$ & $11.7(8.5)$ & $8(67)$ & $3(25)$ & $1(8)$ & - \\
\hline Respimat ${ }^{\circledR}$ Bad inhalation technique $(\mathrm{n}=27)$ & $6(5-7)$ & $12.5(3.6)$ & $33.6(7.1)$ & $8.5(5.7)$ & $17(63)$ & $4(15)$ & $6(22)$ & - \\
\hline
\end{tabular}

IC, inhalation chamber; pMDI, pressurized metered dose inhalers; ${ }^{*} \mathrm{p} \leq 0.05$. 


\section{Conclusions}

This study describes a lack of knowledge and practical abilities about aerosol therapy of HCPs of a large Italian teaching hospital. The poor knowledge and skills in using inhalers can limit these health care providers in training and assessing proper IT of their patients. Among all the participants evaluated, respiratory physiotherapists and pneumologists showed better competencies than other professionals.

\section{References}

1. Global Initiative for Asthma. Pocket guide for asthma management and prevention (for adults and children older than 5 years). 2020. Available from: https://ginasthma.org/pocketguide-for-asthma-management-and-prevention/

2. Global Initiative for Chronic Obstructive Lung Disease. Gold Pocket Guide 2019.

3. Sanchis J, Gich I, Pedersen S, Aerosol Drug Management Improvement Team. Systematic review of errors in inhaler use: Has patient technique improved over time? Chest 2016;150:394-406.

4. Capanoglu M, Dibek Misirlioglu E, Toyran M, et al. Evaluation of inhaler technique, adherence to therapy and their effect on disease control among children with asthma using metered dose or dry powder inhalers. J Asthma 2015;52:838-45.

5. Momeni S, Nokhodchi A, Ghanbarzadeh S, Hamishehkar H. The effect of spacer morphology on the aerosolization performance of metered-dose inhalers. Adv Pharm Bull 2016;6:257-60.

6. Westerik JA, Carter V, Chrystyn H, Burden A, et al. Characteristics of patients making serious inhaler errors with a dry powder inhaler and association with asthma-related events in a primary care setting. J Asthma 2016;53:321-9.

7. Plaza V, Lopez-Vina A, Entrenas LM, et al. Differences in adherence and non-adherence behaviour patterns to inhaler devices between COPD and asthma patients. COPD 2016;13:547-54

8. Plaza V, Giner J, Rodrigo GJ, et al. Errors in the use of inhalers by health care professionals: A systematic review. J Allergy Clin Immunol Pract 2018;6:987-95.

9. Melani AS. Inhalatory therapy training: a priority challenge for the physician. Acta Biomed 2007;78:233-45.

10. Chopra N, Oprescu N, Fask A, Oppenheimer J. Does introduction of new "easy to use" inhalational devices improve medical personnel's knowledge of their proper use? Ann Allergy Asthma Immun 2002;88:395-400.

11. Alismail A, Song CA, Terry MH, et al. Diverse inhaler devices: A big challenge for health-care professionals. Respir Care 2016;61:593-9.

12. Esposito S, Brivio A, Tagliabue C, et al. Knowledge of oxygen administration, aerosol medicine, and chest physiotherapy among pediatric healthcare workers in Italy. J Aerosol Med Pulm Drug Deliv 2011;24:149-56.

13. Douglas S, Gardenhire DB, Shawna Strickland, et al. A guide to aerosol delivery devices for respiratory therapists. American Association for Respiratory Care; 2017.

14. Fink JB, Rubin BK. Problems with inhaler use: a call for improved clinician and patient education. Respir Care 2005;50:1360-74; discussion 74-5.

15. Team RDC. A language and environment for statistical computing. R Foundation for Statistical Computing. 2015.

16. Rau JL. Practical problems with aerosol therapy in COPD. Respir Care 2006;51:158-72.

17. Sestini P, Cappiello V, Aliani M, et al. Prescription bias and factors associated with improper use of inhalers. J Aerosol Med 2006;19:127-36.

18. De Blaquiere P, Christensen DB, Carter WB, Martin TR. Use and misuse of metered-dose inhalers by patients with chronic lung disease. A controlled, randomized trial of two instruction methods. Am Rev Respir Dis1989;140:910-6.

19. Gambazza S, Carta F, Brivio A, Colombo C. Aerosol delivery practice in Italian Cystic Fibrosis centres: a national survey. Arch Physiother 2016;6:1. 